\title{
Os paradigmas da imprensa na cobertura das políticas ambientais
}

\author{
Katarini Miguel*
}

\section{Resumo}

Este artigo apresenta os principais resultados da pesquisa "Os paradigmas da imprensa na cobertura das políticas ambientais", que teve como objetivo central delinear as características das notícias sobre os temas diretamente relacionados com a política ambiental do Brasil. O trabalho teve como suporte teórico o resgate histórico dos paradigmas científicos e ambientais, que foi, posteriormente, complementado pela sistemática Análise de Conteúdo, com abordagem quantitativa e qualitativa, das publicações veiculadas no jornal $O$ Estado de $S$. Paulo durante o ano de 2007. Pela avaliação, a cobertura ambiental é intensa e constante, mas reproduz paradigmas antropocêntricos, positivistas, não compreende a totalidade do meio ambiente, além de reiterar uma visão economicista e de natureza utilitária.

Palavras chave: Paradigmas. Meio Ambiente. Jornalismo. O Estado de S.Paulo. Comunicação Científica.

\section{The paradigms of media coverage of environmental policy Abstract}

This article presents the main results of the research "The paradigms of media coverage of environmental policy " which aimed to outline the central features of stories on topics directly related to politics Brazil's environmental. The work was theoretically supported the historic rescue of scientific paradigms and the concept of environment, which was later supplemented by systematic content analysis with quantitative and qualitative approach, the publications circulated in the newspaper O Estado de S. Paulo during the year 2007. Upon

\footnotetext{
* Doutoranda no Programa de Pós-Graduação em Comunicação, Faculdade de Comunicação, Universidade Metodista de São Paulo - São Bernardo do Campo, SP, Brasil. Mestre em comunicação pela Universidade Estadual Paulista. Jornalista, com experiência em comunicação ambiental, atuou por 12 anos em ONGs e instituições ambientalistas. Membro do Grupo de Pesquisa Comunicação e Linguagem e bolsista CNPq. E-mail: k-miguel@uol.com.br.
} 
evaluation, the environmental coverage is intense and constant, but reproduces anthropocentric paradigms, positivist, does not cover the entire environment, in addition to reiterating a view of economist and utilitarian nature.

Keywords: Paradigms. Environment. Journalism. O Estado de S.Paulo. Science Communication.

\section{Los paradigmas de la cobertura mediática de la política ambiental Resumen}

Este artículo presenta los principales resultados de la investigación "Los paradigmas de la cobertura mediática de la política ambiental" que tuvo por objetivo analizar las características centrales de las noticias sobre temas directamente relacionados con la política de medio ambiente brasileña. El trabajo fue apoyado teóricamente en el rescate histórico de los paradigmas científicos y de medio ambiente, que fue complementado posteriormente por análisis de contenido sistemático con enfoque cuantitativo y cualitativo, das publicaciones del periódico O Estado de S. Paulo durante el año 2007. Tras la evaluación, la cobertura del medio ambiente es intenso y constante, sino que reproduce los paradigmas antropocéntrico, positivista, no cubre todo el entorno, además de reiterar una visión de economista y de carácter utilitario.

Palabras clave: Paradigmas. Medio Ambiente. Periodismo. O Estado de S.Paulo. Comunicación Científica.

\section{Introdução}

comunicação transformou os modos de experiências e os
padrões de interação das sociedades modernas. Thompson
$(1995$, p.305) aponta que as pessoas agem, em muitos casos, como resposta às mensagens que elas recebem. Para ele, a mídia pode influenciar políticas públicas e tomadas de decisões. Nesse contexto, a relação dos meios de comunicação com o meio ambiente deve ser analisada para constatar de que forma se dá a participação da mídia no processo de discussão das questões ambientais. Ainda quando se considera o exercício político, faz-se necessário analisar a construção destas notícias para reconhecer os paradigmas que ainda persistem nas mensagens e, consequentemente, influenciam a visão do leitor e podem comprometer políticas públicas. A temática ambiental é hoje frequente e abundante nos veículos de comunicação, sendo protagonista de amplas reportagens e cobertura e, nesse sentido, mostra-se como 
um importante campo de estudos e pesquisas para compreender as relações e as significações entre sociedade, meio ambiente e cultura midiática.

Com base em toda essa problemática, o presente artigo evidencia os principais resultados da dissertação de mestrado que justamente investigou o tratamento da informação ambiental, identificando as características da imprensa contemporânea na abordagem diária dos fenômenos ambientais, a partir da análise do jornal impresso O Estado de S.Paulo, no ano de 2007.

O período mostrou-se bastante peculiar para avaliação da cobertura ambiental por conta da publicação dos relatórios sobre causas e consequências das Mudanças Climáticas, do IPCC (Painel Intergovernamental de Mudanças Climáticas), o que levantou discussões sobre a necessidade de alternativas aos combustíveis fósseis, colocando em pauta o tema dos biocombustíveis e a produção de etanol. Dentro desse contexto, o então presidente norte-americano George W Bush visitou o Brasil para selar acordos para a produção de etanol, sob a chancela da preocupação ambiental. Além disso, a Campanha da Fraternidade da CNBB (Conferência Nacional dos Bispos do Brasil), com o lema "Fraternidade e Amazônia" colocou em pauta a preservação da Amazônia e o futuro da maior floresta do planeta. Também foi o ano da liberação da comercialização de alimentos transgênicos pela CTNBio (Comissão Técnica Nacional de Biossegurança), e do início da transposição das águas do rio São Francisco, gerando discussões sobre a revitalização dos recursos hídricos. Os acontecimentos rechearam a imprensa de publicações ambientais, gerando o que se arrisca a denominar como o "boom" da preocupação ambiental.

O diferencial desta pesquisa foi embasar as análises na compreensão de que a visão de natureza e meio ambiente moldou-se a partir de diferentes paradigmas científicos, com isso, buscou identificar as reminiscências desses paradigmas na cobertura midiática. Desde a concepção primitiva com as representações por meio das figuras rupestres, que mostravam o homem necessariamente como dominador da natureza, passando pelo Renascimento, pelo paradigma Positivista, que proporcionou a visão utilitária de meio ambiente, até chegar à ascensão da temática e no protagonismo 
dos movimentos ambientais na difusão da causa ambiental, sempre levando em consideração o papel da mídia neste processo. Foi necessário também, entender o contexto ambiental cientificamente, para, então, averiguar suas representações dentro da estrutura midiática. Por meio de autores como Thomas Huxley, que, em 1866, avaliou a interdependência dos seres humanos com os demais seres vivos sinalizando para uma conceitualização de meio ambiente. Mais adiante, Boff (2000) resumiu a ecologia como as condições e relações que formam o habitat de cada um dos seres da natureza, em uma complexa relação e 'inter-ação'. Mas o conceito de meio ambiente foi por muito tempo reduzido exclusivamente a questões de fauna e flora, não concebendo a necessária interdependência com fatores sociais, culturais, políticos e econômicos. Quando se avalia a abordagem ambiental na mídia, a tendência não é diferente.

Vale ressaltar que a escolha pelo veículo impresso se deu pela maior abrangência da temática, possibilidade de análises, interpretação de dados, investigação e crítica sem censura ou ameaça de repressão. Mas considerando, obviamente, as limitações econômicas deste tipo de jornalismo, que atua enquanto indústria dependente dos recursos financeiros oriundos, em sua maioria, da publicidade e propaganda. Além disso, o Estadão apresenta uma característica peculiar para a pesquisa: ao mesmo tempo em que é o jornal que mais exerce influência entre as empresas brasileiras, segundo pesquisa Credibilidade da Mídia (2008), realizada pela CDN (Companhia de Notícias), tem forte ligação com o ambientalismo no Brasil. Seus dirigentes foram fundadores de uma das maiores ONGs ambientais do país, a Fundação SOS Mata Atlântica. Neste sentido, mostra-se interessante avaliar como esta dualidade entre mercado produtivo e ambientalismo transparecem nas páginas do jornal.

O Estado de S.Paulo deu ampla cobertura e visibilidade ao tema ambiental, que esteve presente em praticamente todas as suas edições durante os 10 meses analisados, de fevereiro a novembro de 2007. O procedimento quantitativo da pesquisa de mestrado, que não será apresentado aqui, mas é relevante retomar, comprovou a alta frequência e intensidade do tema ambiental no jornal, em sua 
abordagem jornalística factual, ou seja, foram abarcados pela pesquisa textos da cobertura diária, desconsiderando produtos opinativos como editoriais, artigos, colunas ou mesmo cadernos especiais. Foram contabilizadas nos 292 dias do período, 774 matérias com viés ambiental, contemplando os temas-eixo, diretamente relacionados com a política ambiental do Brasil, sendo: Biodiversidade, Biocombustível, Aquecimento Global/ Mudanças Climáticas. As publicações, todas de caráter noticioso, foram devidamente classificadas por datas, títulos, editorias, temas, frequência de fotos, infográficos e chamadas de capa, além de fontes de informação, oferecendo um panorama geral e mensurável da amostra. Vale ressaltar que o jornal trouxe grandes reportagens sobre o assunto, resultando em até nove matérias sobre a temática em uma única edição (26/08/2007). Foi verificada a ausência do tema ambiental no jornal, na perspectiva proposta, em apenas 13 dias (4\%).

A partir desta quantificação, foi possível selecionar 12 dias de coberturas para a análise qualitativa, levando em consideração o destaque das publicações (manchetes, infográficos, fotos, chamadas de capa) e espaço (abrangência) que obtiveram no jornal em cada mês da coleta, buscando diversificar as temáticas para compor um amplo panorama da cobertura ambiental e, assim, identificar os paradigmas predominantes.

A metodologia utilizada para essa fase de aprofundamento foi a Análise de Conteúdo, estudada por Bardin (1977) com a contribuição de Fonseca Junior (2008), que contempla estudos quantitativos para avaliar a frequência de certas características no conteúdo, assim como qualitativos, visando identificar as estratégias e composições de texto, que imprimem determinados significados. Abarcando, especialmente, o processo de inferência para avaliar os aspectos implícitos na mensagem e compreender as significações como mitos, símbolos e valores. Também são utilizados como autores específicos do trabalho com textos jornalísticos, Charaudeau (2006) e Sousa (2004) que atuam com uma sistemática análise qualitativa, e indicaram categorias a serem contempladas pela pesquisa, como os procedimentos de objetivação - com análise das fontes de informação e verbos de declaração, seleção e hierarquização dos acontecimentos, citações escolhidas, significado 
no contexto, adjetivação das fontes e declarações. Também os procedimentos de intensificação e dramatização - como o uso de vocábulos, palavras e adjetivos que gerem exagero, simplificação, oposição, deformação e amplificação emocional na mensagem. E por fim, foram considerados ainda nas avaliações de cada texto os procedimentos de persuasão - que priorizam a menção das causas dos acontecimentos, construção de textos emotivos, com superioridade de determinados argumentos, evidenciando vantagens e desvantagens da situação e referências hipotéticas.

Otrabalho também se atentou às características da imprensa na cobertura dos fenômenos e aos indicativos do discurso midiático, que evidenciam as escolhas e os critérios dos veículos de comunicação que, de certa forma, direcionam também o tratamento da questão ambiental. Para despertar o interesse e "seduzir" o leitor, o jornalismo recorre a estratégias de linguagem, que acabam por produzir um efeito de banalização, saturação e dramatização do assunto. Tais estratégias foram identificadas e exemplificadas, proporcionando um entendimento mais concreto das abordagens.

São apresentados, portanto, na sequencia, a título de amostragem e comprovação dos resultados da dissertação, o trabalho prático de análise de conteúdo de dois significativos conjuntos de matérias, em dois dias diferentes de cobertura, com os temas-eixo Aquecimento Global e Biodiversidade, que ilustram a pesquisa realizada e dão pistas concretas a respeito dos resultados obtidos.

\section{Análise do corpus}

1. TEXTO: O Estado de S.Paulo, 3 fev. 2007

Caderno Geral

Chapéu: IPCC: Mudanças Climáticas

Título: Efeitos do aquecimento da Terra são irreversíveis nos próximos 100 anos

Linha Fina: Relatório conclui que o homem é responsável pelo efeito estufa e prevê consequências rápidas e violentas.

Disponível em: http://infoener.iee.usp.br/infoener/hemeroteca/ imagens/100523.htm 
A reportagem, escrita por jornalista do próprio jornal, divulga a publicação do $1^{\text {o }}$ relatório do IPCC (Painel Intergovernamental de Mudanças Climáticas) ligado à ONU, elaborado por mais de dois mil cientistas de 130 países, cinco anos após o último relatório do painel. $\mathrm{O}$ documento mostra mais claramente e com detalhes as causas e repercussões das mudanças climáticas e seus efeitos nos diversos países. $\mathrm{O}$ assunto é manchete principal do jornal, que traz em letras garrafais na capa: "Aquecimento global é irreversível", com os tópicos como linha fina: "Fórum internacional conclui que emissão de gases comprometeu o clima nos próximos 100 anos"; "Mudança será 'intensa, longa e violenta', dizem cientistas"; "Previsão de mais tempestades, furacões, inundações e seca". Uma foto grande e impactante mostra uma cidade destruída por um tornado nos Estados Unidos, com a legenda "Natureza em fúria". A chamada ocupa mais de $1 / 2$ página da capa do jornal em uma edição de sábado, com outra chamada logo abaixo "Brasil sofrerá efeitos graves no litoral e na Amazônia". Também na capa, ilustrações trazem os efeitos do aquecimento, mostrando os termômetros subindo e as consequências de cada grau de aumento de temperatura. Ao lado, o título "A sobrevivência será mais difícil" chama para uma entrevista com um físico brasileiro. Na capa é reproduzida declaração do diretor do Programa da ONU para o Meio Ambiente, Achim Steiner: "2 de fevereiro de 2007 será lembrado como o dia em que o ponto de interrogação sobre a responsabilidade do homem sobre as mudanças climáticas foi removido".

No contexto da capa, é possível notar o grande destaque dado à questão, que traz manchete, ilustrações, chamadas para entrevistas e declarações de forte conteúdo emotivo. $\mathrm{O}$ enfoque dramático, priorizado pelo jornal, é fortalecido com a foto, em grandes proporções, que evidencia um cenário de desespero, representando a destruição causada pelo aquecimento global. As afirmações ao longo do texto reiteram a intensificação - a mudança será "violenta" e "previsão de mais tempestades".

O texto da chamada ainda traz logo nas primeiras linhas a afirmação: "E a culpa não é de fatores naturais, mas da atividade humana". Nota-se, nesse sentido, que a natureza é posicionada enquanto mãe - a preservação garante a sobrevivência do homem 
na terra - e madrasta - ela é rude, pode se vingar. A culpa, do aquecimento, é atribuída ao homem, sem especificar quem é este homem. A generalização coloca todos os homens na mesma situação de co-responsabilidade, desconsiderando as diferenças sociais, culturais e, inclusive, econômicas.

A chamada é construída com informações do relatório do IPCC, mas não há citação, nesse primeiro momento, extraída literalmente do documento, deixando de lado o procedimento de objetivação jornalística. Ainda na abordagem da capa, há um forte procedimento de persuasão e o jornal deixa claro que não há atitude que possa ser tomada, dando um tom catastrófico à questão: "Até 2100, a temperatura média da Terra subirá 3ㄷ, mesmo que medidas sejam tomadas da noite para o dia”, afirma.

O texto de gênero noticioso é escrito em estilo reportagem, com interpretação dos dados, infográficos e imagens, alocado na editoria Vida \&, em um espaço privilegiado de três páginas inteiras, de uma edição de sábado. A reportagem tem início com um evidente procedimento de intensificação e exagero, utilizado, por vezes, para ampliar a atenção ao assunto "o aquecimento global e as mudanças climáticas chegaram a uma velocidade e com uma violência muito maiores do que os cientistas e governantes esperavam", mas não explica o que era esperado. E outras afirmações dramatizadas: "a situação só vai piorar"; "Em alguns anos o extremo será comum"; "O efeito é mais devastador do que o próprio IPCC imaginava”, insistindo novamente em um cenário já esperado, sem, contudo, descrevê-lo. A utilização de adjetivos e substantivos como devastador, extremo e violência evidencia o enfoque dramático escolhido para o tratamento do tema.

A construção de texto, emotivo e pouco objetivo, contribui para o procedimento de persuasão. As referências hipotéticas e pouco exatas, formuladas com os verbos no futuro e utilizando advérbios de dúvida, também mostram o viés catastrófico: "o gelo diminuirá no Ártico e talvez na Antártida, alterará a salinidade da água e aumentará o volume de precipitações”. O documento do IPCC é utilizado como fonte generalizada, sem citação direta de trechos do relatório, por exemplo. A única declaração usada literalmente é a mesma reproduzida na capa do jornal em que o di- 
retor do programa da ONU para o Meio Ambiente afirma que não há mais dúvidas que a culpa do aquecimento global é do homem.

Dentro do procedimento de objetivação e escolha das fontes, a reportagem conta com um quadro de declarações sobre as reações de líderes mundiais mediante o conteúdo do relatório do IPCC - o presidente da França, ministros do Meio Ambiente italiano, sul-africano e indiano e porta - voz do presidente dos Estados Unidos, concordando com a gravidade do problema e revelando uma situação, no mínimo, crítica. As fontes do setor político mundial têm forte efeito de decisão e são utilizadas para reiterar a importância do assunto. Apenas a declaração do ministro indiano é ambígua e até mesmo contrária aos posicionamentos anteriores: "É um grupo de especialistas em clima tentando chegar a um consenso científico. Isso não obriga os governos a se comprometerem com nenhuma ação concreta". Mas esta declaração foi reproduzida de forma isolada e não foi desenvolvida pela reportagem.

A causa do aquecimento, colocada em questão, é o homem, principalmente por conta da dependência de combustíveis fósseis e desmatamento de florestas, mas não entra em méritos científicos e mais profundos das causas, focando-se nas prováveis consequências e, para isso, utiliza os piores resultados previstos pelos cientistas. As projeções efetuadas pela reportagem, por meio do uso de infográficos, evidenciam o apelo e persuasão. $\mathrm{O}$ quadro "os possíveis mundos do futuro", mostra o melhor e o pior cenário, com referências hipotéticas e catastróficas. $\mathrm{O}$ texto que acompanha busca detalhar os resultados do aumento da temperatura - "Riscos que o mundo está sujeito com o aumento da temperatura".

Uma nota como adendo traz a repercussão norte-americana "EUA ajudaram no relatório. E sem fazer objeções", que coloca que a grande surpresa foi o posicionamento do país, que não fez considerações sobre o documento. Como fonte de informação da nota está um porta-voz norte-americano, não identificado, que elogia o trabalho do IPCC, e o secretário de energia americano, Samuel Bodman, que minimiza a responsabilidade dos EUA no processo de aquecimento. Nota-se que o texto busca dar destaque à polêmica com relação à interferência dos países, em especial, os EUA, em relatórios científicos sobre as causas e consequências 
do aquecimento global, mas sem respaldo objetivo. Além disso, é nítida a escolha por fontes oficiais para mostrar o efeito de decisão dos personagens e evidenciar a influência e eficiência do jornal ao conseguir depoimentos exclusivos.

Uma página inteira do jornal é dedicada à ilustração "Involução Terrestre", que mostra as práticas do homem que ocasionaram o cenário atual, e as implicações das atividades até 2100, evidenciando um cenário catastrófico, em um procedimento de persuasão e intensificação, com afirmações como "18 mil ilhas desaparecerão", "Savanização da Amazônia”, "tempestades mais frequentes". Não há citação direta à fontes de informação.

A reportagem ainda traz, na mesma edição, duas matérias relacionadas diretamente com os impactos das mudanças climáticas no Brasil e o posicionamento do Ministério do Meio Ambiente.

A matéria "Lobby brasileiro reduz influências das queimadas" (linha fina: "Delegação conseguiu deixar em 15\% parâmetros de participação da prática na emissão de CO2; Amazônia foi tema mais debatido no painel"), aborda a pressão dos delegados brasileiros para conseguir que o IPCC diminuísse os parâmetros que determinam a influência do desmatamento no total de emissão de gás carbônico, principal causador do aquecimento global. No entanto, na nota anterior, já mencionada na presente análise, o jornal avaliou que os governos pouco influenciaram nos resultados no relatório, mas a abordagem desta matéria mostra forte contrariedade. Mais um detalhe de inconsistência de informações é que a nota anterior sequer citou o Brasil e a matéria principal não fez relação direta nenhuma com a Amazônia, apenas no infográfico, e nesta matéria é afirmado que a Amazônia foi o tema mais debatido no painel, relativo ao Brasil. Vale ressaltar que os textos são escritos pelo mesmo jornalista, tornando mais difícil justificar as incongruências.

A única fonte de informação direta utilizada nessa matéria é o cientista brasileiro, membro do IPCC, Paulo Artaxo, que explica que as queimadas são causa do aquecimento, mas o prioritário é reduzir a queima de combustíveis fósseis. Há também referência indireta ao relatório do IPCC, se servindo dos trechos mais impactantes: "Se concretizada a alteração climática, a Amazônia, tal como é conhecida hoje, tenderá à extinção, cedendo lugar a 
uma savana semelhante ao cerrado do Centro-Oeste". Este tipo de comparativo, feito pelo próprio jornalista, sem fontes de informação, gera dúvidas no leitor leigo sobre a relevância do bioma Cerrado, um dos mais degradados dos últimos anos. Ao avaliar que a Amazônia deve se findar em Cerrado, o jornal/jornalista desconsidera a importância do referido bioma e sua rica biodiversidade. Ainda é possível notar, pela escolha das declarações das fontes, o impacto que se quer alcançar "O aquecimento trará alterações dramáticas para o sistema”. E trabalha com hipóteses "Outro previsível impacto...", que coloca em destaque um tipo de reação em detrimento de outro.

$\mathrm{Na}$ mesma cobertura o jornal traz a problemática para o âmbito da política ambiental brasileira na matéria "Brasil não está preparado, diz Marina Silva" (linha fina: "Para ministra, países pobres serão os mais afetados pelo efeito estufa"). Apesar de trazer a problemática global para o âmbito local, o texto prioriza o enfoque dramático sem acrescentar elementos ou propostas à discussão ambiental. $\mathrm{O}$ jornal coloca que a ministra admite que o Brasil não está preparado para enfrentar os efeitos do aquecimento global e que os cientistas estão preocupados. Verbos como admitir, enfrentar e preocupar dão o tom dramático à questão.

Além da ministra, são utilizados como fontes de informação cientista que integra o IPCC, José Antonio Marengo, e o pesquisador da Embrapa Eduardo Assaf, que utilizam os cenários mais pessimistas (e assumem a escolha) em um procedimento de intensificação e exagero com argumentações inconsistentes. As consequências para a produção de alimento, segundo estudo da Universidade Estadual de Campinas e Inpe (Instituto Nacional de Pesquisas Espaciais), reproduzida pelo jornal no seu aspecto mais negativo, é a redução de $70 \%$ da produtividade da soja. A solução colocada, segundo o texto, seria o desenvolvimento de sementes transgênicas, resistentes ao clima. Aqui, o jornal se esquiva da discussão sobre os transgênicos, colocando-os como solução para o aquecimento, sem contestações. Também avalia o plantio de eucalipto como benéfico, sem esclarecer que se trata de uma espécie exótica, que exibe muitos problemas à biodiversidade nacional. $\mathrm{Ou}$ seja, reproduz declarações de especialistas com efeito de saber, mas 
sem conhecimento prévio do assunto, para questionar e entrar em méritos científicos e técnicos da questão. E generaliza: "Todos são unânimes em afirmar que o combate ao desmatamento é tarefa número um a ser perseguida no país”. A entrevista com físico brasileiro, integrante do IPCC, na mesma cobertura traz o título hiperbólico: "Guerras mundiais são fichinha perto disso". A entrevista estilo ping-pong, faz perguntas alarmistas "Então a Terra está condenada?", pergunta o jornalista, "não, não é o fim do mundo", responde a fonte, no entanto, o jornal insiste nessa abordagem alarmista. A entrevista é curta e superficial, não entra em méritos científicos, mas discute a eficiência do relatório, se centrando em corroborar as decorrências desastrosas para a humanidade.

Vale comentar que a abordagem catastrófica e alarmista predominante nesta cobertura pode render pautas atrativas, mas pouco informativas. A exemplo desse conjunto de textos, pelo menos outros três dias de cobertura analisadas qualitativamente apresentaram as mesmas características: "Mundo tem dinheiro e tecnologia para frear aquecimento, diz IPCC"(30/04/2007); "Lula ataca compromisso parcial do G-8 para conter efeito estufa" (08/06/2007) e "Impacto de mudança climática é irreversível" $(17 / 11 / 2007)$. Além disso, o tema do aquecimento global foi o mais frequente na cobertura, totalizando mais de 23\% das matérias contabilizadas e na parte qualitativa,

É possível afirmar, que no caso do aquecimento global, a escolha foi por uma cobertura centrada nas consequências das mudanças climáticas, reproduzindo os piores cenários e a necessidade de mitigação e não de adaptação às circunstâncias. Além disso, a problemática é tratada distanciada da realidade do leitor, com efeitos para o Ártico, Antártica e Amazônia. O homem não é parte da natureza, mas é colocado como culpado pelos desastres e vai sofrer as consequências, o que reforça o paradigma antropocêntrico da questão. A ideia de natureza vingativa, que é necessário controlá-la, remonta ao pensamento grego, que acreditava na fúria da natureza. Os rituais sagrados do primitivismo também visavam harmonizar-se com a natureza e vencer os próprios temores com relação às consequências naturais. Mais tarde, no final da Idade Média, se intercruzam os ideais de natureza enquanto mãe prote- 
tora e madrasta vingativa. Nesse sentido, antigos paradigmas são reproduzidos na reportagem analisada, que evidenciam a natureza enquanto força vingativa, e coloca o homem como sujeito isolado e responsável pelas mazelas ambientais.

\section{TEXTO: O Estado de S.Paulo, 15 ago. 2007 \\ Caderno Geral}

Chapéu: Gestão

Título: Plano contra desmatamento focará em economia da floresta Linha Fina: Governo dará enfoque à fiscalização para planos de manejo e reaproveitamento de áreas

Disponivel em: http://www.estadao.com.br/estadaodehoje/20070815/not_imp34862,0.php

Nesta edição de quarta-feira, dia da temática ambiental na editoria Vida \&, o jornal traz matéria ambiental com grande destaque. A chamada, porém, não ganhou muito espaço, ocupando um pequeno trecho na parte inferior direita da capa, que anuncia "Exploração econômica da floresta terá plano oficial". Vale colocar que a matéria mesmo não sendo manchete foi escolhida pela temática Biodiversidade, que além de ser um dos temas-eixo, traz indícios importantes para as análises. Do total quantificado, Biodiversidade respondeu por $21 \%$ dos textos, atrás apenas da pauta do Aquecimento Global.

Voltando à chamada, a mesma anuncia que o governo deve lançar o Plano de Prevenção e Controle do Desmatamento da Amazônia, voltado para exploração econômica da floresta. Sem fontes de informação, até pelo tamanho da nota na página, a abordagem sinaliza para o consenso entre a preservação e os incentivos econômicos, exaltando logo de início, de maneira bastante positiva, que a exploração econômica sustentável da floresta pode tornar a região exportadora de produtos florestais.

A matéria interna ocupa quase toda a página da editoria Vida\& e anuncia - "Plano contra desmatamento focará em economia da floresta". Matéria enquadrada na temática Meio Ambiente, com o chapéu Gestão, gênero noticioso, escrita por jornalista do próprio jornal. 
Como uma das fontes de informação está o então secretário executivo do Meio Ambiente, João Paulo Capobianco, que na declaração escolhida e reproduzida pelo jornal como exclusiva, justamente para criar efeito de decisão e credibilidade/ exclusividade do jornal, reforça o aspecto econômico: "Temos que sair do papo furado e criar uma economia florestal de fato na Amazônia”, frisando falta de alternativas econômicas em áreas preservadas e defendendo a utilização econômica. Outra fonte, o cientista do Inpe (Instituto Nacional de Pesquisas Espaciais), Carlos Nobre também frisa a importância de uma alternativa de desenvolvimento sustentável para a área. As fontes, com efeitos de decisão e de conhecimento, acabam por respaldar a posição do jornal, que se revela através da perspectiva das fontes, como lembra Charaudeau (2006).

Os dados de desmatamento reproduzidos pelo jornal são do próprio governo e informações do cientista do Inpe, que declara "mas ainda estamos muito longe, muito longe mesmo de cantar vitória" - declaração que reflete um procedimento de intensificação, pois não acrescenta informação, apenas reforça a gravidade do fato. Em outra declaração "A tecnologia para reaproveitamento de áreas degradadas é absolutamente insuficiente, completamente irrisória" (sobre reaproveitar áreas desmatadas e não só florestas) não justifica o porquê não se pode utilizar economicamente áreas que já estão desmatadas.

Os procedimentos de intensificação se misturam com os elementos de persuasão em construções como "principais forças que impulsionam o desmatamento (...) é a falta de alternativas econômicas". Um intrigante questionamento feito pelo próprio jornal evidencia o posicionamento utilitarista: "O governo federal depara-se com novo dilema: o que fazer com florestas que não foram desmatadas?" - como se floresta em pé não trouxesse benefício algum. Assumindo, desde o primeiro parágrafo, que a floresta precisa de utilidade econômica, desconsiderando os serviços ambientais prestados como equilíbrio térmico, regulação de chuvas, manutenção da biodiversidade, etc. Refletindo uma visão estritamente antropocêntrica de que o homem deve dar utilidade à natureza, reforçada pelas afirmações persuasivas - "no lugar de 
toras, móveis e artesanatos", a biodiversidade tem "milhares de produtos a oferecer".

Os procedimentos de persuasão são notados pelas fontes de informação escolhidas para reiterar valor econômico que precisa ser retirado da floresta. $\mathrm{O}$ fato é que o jornal se apropria de fontes governamentais sem contestação, com o efeito de decisão para respaldar o próprio posicionamento.

A ilustração da matéria mostra mapa das Unidades de Conservação Federal e Estadual da Amazônia Legal (terra indígena, proteção integral, uso sustentável e não definidas) com o título "Rede de Proteção". E um gráfico ao lado "Destruição em queda" que traz os índices anuais de desmatamento desde 77/88, mostrando queda a partir de 2004. O mapa ilustra os pontos que estão preservados por unidades de conservação com a informação de que cerca de $24 \%$ do território está protegido por lei - ou seja, locais que não trazem lucro.

Em uma nota, que faz parte da matéria principal, "MMA pode preencher cargo por critérios técnicos", a fonte é o sub-secretário de coordenação das Unidades de Pesquisa do Ministério de Ciência e Tecnologia, Luiz Fernando Schettino, que em nota comenta que o Ministério do Meio Ambiente deveria preencher cargos por critério técnico e não indicação política. A nota não tem relação direta com a matéria principal, mas ressalta, talvez, que o Ministério precisa de pessoas mais competentes e especializadas em seus quadros.

A reportagem busca o consenso, pouco provável, como lembra Dutra (2005), entre desenvolvimento econômico e preservação, além de fazer uso indiscriminado do termo desenvolvimento sustentável, sem se ater ao real significado do termo. Nenhuma fonte do "outro lado" foi ouvida, que contestasse, por exemplo, exploração econômica da floresta, ainda que de maneira sustentável. Os procedimentos de persuasão evidenciam a construção dos argumentos favoráveis à economia da floresta, deixando óbvio também o posicionamento e o perfil editorial do jornal, que reproduz um paradigma positivista, ao frisar o valor econômico-utilitário da natureza. 


\section{Considerações e discussões}

que se apresentou aqui foi uma singela, porém significativa parte de uma extensa pesquisa de mestrado que primou pela abrangência, quantificando todas as matérias, veiculadas no Estadão, diretamente relacionadas com a política ambiental do Brasil no período de 10 meses, fevereiro a novembro de 2007, realizando posteriormente a análise qualitativa de 13 publicações, o que permitiu alcançar resultados importantes sobre os paradigmas predominantes da mídia, que consequentemente podem influenciar a visão do leitor e comprometer políticas públicas para a área. Será possível aqui abranger as discussões para se ter um panorama geral da pesquisa e de todos seus resultados.

A primeira constatação importante foi referente à quantidade de matérias e o espaço que a temática ocupou no jornal. Foram, no total, 774 publicações, o que representa uma média de três matérias por dia, sem contar os cadernos especiais e suplementos semanais que não fizeram parte da amostra. Os textos foram enquadrados em todas as editorias do jornal, com exceção de Esportes, sendo Vida \& e Economia os principais espaços da temática, o que evidencia a interdisciplinaridade do tema, as diferentes facetas dadas à questão, mas não representa a pluralidade de abordagens. As matérias ambientais tiveram destaque significativo - 20\% delas contaram com chamada de capa, e mais de 56\% trouxeram elementos externos ao texto como fotos, ilustrações e infográficos. A quantidade de informações e o espaço conquistado em diferentes seções do jornal são fatores positivos para uma temática antes marginalizada, que hoje ganha centralidade. É certo que a questão ambiental é impulsionada em datas especiais, publicações de relatórios, divulgação de números e dados de desmatamento, e ainda não consegue transitar de modo adequado pelas diversas pautas do cotidiano.

Ficou evidente, a partir da análise quantitativa que $O$ Estado de S.Paulo, incorporou o discurso da preocupação ambiental, desenvolvimento sustentável, produção de energia e combustíveis alternativos, mas deixou a desejar na abordagem informativa, como foi possível notar com mais clareza nas análises qualitativas. As 
fontes oficiais foram maioria nos textos e quando se deu espaço para grupos minoritários e alternativos foi apenas para confirmar os argumentos já colocados ou mesmo para revelar embates, o que confirma a colocação de Charaudeau (2006) de que o jornal dá o espaço apenas para aparentar um discurso democrático. As fontes, mesmo em lados opostos, tinham os mesmos argumentos, mas geravam a falsa impressão de discursos antagônicos. Além disso, muitas fontes foram colocadas sem denominação específica, como foi o caso de "ambientalistas" e "especialistas", o que pode significar desconhecimento por parte do jornalista ou ainda generalização de uma afirmação do senso comum, sem considerar a diversidade dos grupos existentes em cada setor. As pessoas que vivenciam diretamente as problemáticas ambientais como comunidades, ribeirinhos e indígenas não tiveram espaço na cobertura, o que permite afirmar que o jornal sofre da Síndrome Lattes, como denomina Bueno (2007), uma vez que só dá espaço para fontes que dispõem de currículo acadêmico, ou àquelas com efeito de decisão ou de conhecimento, sob a justificativa da neutralidade e objetividade, minimizando o debate político.

A identificação dos procedimentos de objetivação, intensificação e persuasão contribuiu para denominar as fontes de informação e suas perspectivas, além de selecionar excertos representativos dos textos e de interpretação para a formatação da análise de conteúdo. Ficou evidente o enquadramento conflituoso da cobertura, ressaltando embates ao invés de explicar o assunto para seu leitor, colocando em primeiro lugar, por exemplo, o conflito entre países ricos e pobres sobre as responsabilidades pelo aquecimento global, ao invés de discutir com afinco as causas e consequências do problema e meios de mitigação e adaptação. A relação econômica e de lucro também foi predominante, em especial, na cobertura sobre geração de energia e biocombustíveis, onde valores de investimentos e nomes de empresas foram centrais. As abordagens também estiveram centradas nos custos do aquecimento global para grandes nações, sem focar nos efeitos para as minorias e setores específicos da sociedade.

Mas foi constatado também que o tema ambiental traz forte apelo emocional, e que esta estratégia é amplamente utilizada 
para dar destaque à maioria das matérias, em especial no assunto Mudanças Climáticas/Aquecimento Global, o que pode indicar o anseio pela notícia espetáculo. As fotos e infográficos também evidenciaram este apelo, corroborando os textos com imagens chamativas, ilustrações permeando o texto, que trazem pouca informação mais atraem pelo visual e impacto. Os procedimentos de persuasão são constantemente utilizados com predominância de determinados argumentos em detrimento de outros, utilização de termos e palavras que recorrem ao emocional e dramatizam a questão, colocando em destaque os piores cenários. Convém destacar o discurso ecológico reproduzido pelo jornal, que se vale de uma "linguagem universal", como coloca Dutra (2005) para denominar de forma generalizada e pretensamente conhecida termos como Desenvolvimento Sustentável, Biodiversidade, Ecossistema e Ecologia, que banalizados, acabam formando a tipologia do discurso ecológico contemporâneo.

Os argumentos sobre os prejuízos ao meio ambiente também não entraram no mérito científico da questão e as explicações superficiais e fragmentadas evidenciaram uma ideia, por ora, utilitarista de natureza, com os tais "usos sustentáveis", e ora reforçavam um caráter punitivo, cobrando ações de comando e controle. A matéria na editoria de economia também desconsiderou questões técnicas, para evidenciar, por exemplo, os dados financeiros e incentivar a construção de usinas e investimentos sem considerar os prejuízos ao meio ambiente. Mesmo em matérias mais científicas, que exigiriam certo rigor, não há esclarecimentos de enunciados saídos do campo estritamente científico, ou mesmo a tradução exigida pela divulgação científica. Avalia-se, neste sentido, que os valores científicos se perderam para dar espaço a textos mais emotivos.

O resgate histórico dos paradigmas científicos foi importante, no sentido em que permitiu compreender as interpretações da mídia contemporânea na representação do tema ambiental. A pauta sobre meio ambiente é constante e obrigatória atualmente nos veículos de comunicação, mas ainda não é abordada de maneira adequada, contextualizada, englobando a complexidade do tema. Avaliou-se que reproduz sim ideais positivistas, antropocêntricos, 
e por vezes, sensacionalistas. Ao colocar o homem como centro da questão e não como parte dela - o homem é a vítima e/ou o culpado das mazelas ambientais, e mesmo quando representa o meio ambiente apenas enquanto fauna e flora - a cobertura feita pelo jornal vai ao encontro de um paradigma antropocêntrico, que triunfou no século 17 e resiste até hoje, deixando dúvidas sobre o real compromisso do jornalismo contemporâneo. Ainda devido às relações econômicas, escolha das editorias e abordagens, muitas vezes, pragmática de alguns assuntos, sobressaiu o paradigma positivista, que vê a natureza de forma utilitária, como um recurso para atingir um fim.

$\mathrm{O}$ fato de o homem dominar a natureza remonta a um pensamento primitivo, evidenciado pelas pinturas rupestres, de natureza vingativa, onde a magia estava intrinsecamente ligada à natureza desconhecida, que apresentava perigo ao homem. A abordagem do jornal O Estado de S.Paulo na temática aquecimento global, coloca o homem como culpado pelas mazelas ambientais e que deve "arcar" com as consequências, evidenciando uma relação que figurou na Idade Média de natureza enquanto mãe e madrasta - ela abriga e protege, mas pode se vingar. $\mathrm{O}$ fato é que o jornal não apresenta apenas um paradigma predominante, mas vários que convergem para o mesmo caminho de representar a questão ambiental de forma isolada, fragmentada, prejudicando o leitor na compreensão da temática. Retomando Thompson (1995), que aponta que as pessoas agem, em muitos casos, como resposta às mensagens que elas recebem e que a mídia pode influenciar políticas públicas e tomadas de decisões, pode-se avaliar que a cobertura midiática não contribui para melhoria das condições ambientais em seus diferentes aspectos políticos, sociais, econômicos e naturais.

Mas vale lembrar, reiterando Dutra (2005), que existe uma real dificuldade em abordar uma questão tão abrangente como a ambiental, por conta da indefinição do objeto, sua complexidade e interdisciplinaridade, que envolvem organizações, cientistas, comunidades locais, movimentos sociais e aspectos políticos, econômicos e sociais. A prática do jornalismo, as rotinas produtivas e outras questões que poderiam ser discutidas, não permitem especializações no âmbito da profissão. Também é fácil concluir que a abordagem 
catastrófica e sensacionalista compensa pelo impacto a primeira vista, gerando teoricamente mais interesse no leitor/espectador, mas não formando opiniões e conceitos claros e necessários para se compreender a dinâmica da política ambiental. Não se discute o que leva a este tipo de cobertura, se é uma escolha voluntária, fruto do processo de produção da notícia ou mesmo se é decorrência do perfil editorial do jornal, mas se pondera que a melhora deste quadro poderia acontecer com jornalistas especializados na área, que compreendam o conceito de meio ambiente cientificamente e os meandros da política ambiental, para, então, traduzir ao âmbito midiático. Em suma, o jornal O Estado de S.Paulo mostrou uma ampla cobertura ambiental no que se refere à quantidade, mas não satisfatória em informações, e que ainda reproduz paradigmas antropocêntricos e positivistas, aliados a uma abordagem fragmentada e economicista.

Compreender a predominância de determinadas características e as reminiscências que persistem até hoje, contribui não só com a análise da cobertura ambiental midiática, mas também pode qualificar o debate ambiental na sociedade, em um busca de um jornalismo mais comprometido. Um jornalismo que explique e contextualize os assuntos para seu leitor e compreenda o meio ambiente de forma integrada e revolucionária.

\section{Referências}

AMORIM, C. NETTO, A. Efeitos do aquecimento da terra são irreversíveis nos próximos 100anos. O Estado de São Paulo, p. A26, 3 fev. 2007. Disponível em: http://infoener.iee.usp.br/infoene. Acesso em: 31 jan.2011.

BARDIN, L. Análise de conteúdo. Lisboa: Edições 70, 1977.

BOFF, L. Ecologia, mundialização e espiritualidade. São Paulo: Editora Ática, 2000. BUENO, W. C. Comunicação, jornalismo e meio ambiente: teoria e pesquisa. São Paulo: Mojoara, 2007.

CHARAUDEAU, P. O discurso das mídias. São Paulo: Contexto, 2006.

COMPANHIA DE NOTÍCIAS. Pesquisa credibilidade da mídia 2008. 
Disponível em: http://www.cdn.com.br/cdnportal/arquivo/CDNEP_PesquisaCredibilidade

VApresenta\%C3\%A7\%C3\%A3oEVENTO_14ago08.pdf. Acesso em: 10 out. 2008.

COSTA, L. Comunicação e meio ambiente: a análise das campanhas de prevenção a incêndios florestais na Amazônia. Belém: Núcleo de Altos Estudos Amazônicos (UFPA), 2006.

DUTRA, M.J.S. A natureza da TV: uma leitura dos discursos da mídia sobre a Amazônia, biodiversidade, povos da floresta... Belém: Núcleo de Altos Estudos Amazônicos (UFPA), 2005.

ESCOBAR, H. Plano contra desmatamento focará em economia da floresta.

O Estado de São Paulo, p.A14, 15 ago.200. Disponível em: http://www.estadao.com.br/estadaodehoje/20070815/not_imp34862,0.php. Acesso em: 31 jan.2011.

FONSECA JÚNIOR, W.C. Análise Conteúdo. In: DUARTE, J. BARROS, A. (Orgs.). Métodos e técnicas de pesquisa em comunicação. São Paulo: Atlas, 2008. p.280-315.

MIGUEL, K. Os paradigmas da imprensa na cobertura das políticas ambientais, 2009, 260 f. Dissertação (Mestrado em Comunicação) - Universidade Estadual Paulista, Bauru/SP.

SOUSA, J.P. Introdução a análise do discurso jornalístico. Florianópolis: Letras Contemporâneas, 2004.

THOMPSON, J.B. Ideologia e cultura moderna. Rio de Janeiro: Vozes, 1995. 